\title{
Percutaneous cholecystolithotomy: is gall stone recurrence inevitable?
}

\author{
J J Donald, S Cheslyn-Curtis, A R Gillams, R C G Russell, W R Lees
}

Departments of Radiology

J J Donald

A R Gillams

W R Lees

and Surgery, The Middlesex Hospital, London

S Cheslyn-Curtis

R C G Russell

Correspondence to:

Dr J J Donald, Department of

Radiology, The Middlesex

Hospital, Mortimer Street,

London WIN 8AA.

Accepted for publication

9 August 1993

\begin{abstract}
Using radiological interventional techniques the gall bladder can be cleared of stones with a high success rate. As with any treatment option that leaves the gall bladder in situ there is an accompanying risk of stone recurrence, which is currently unknown for the radiological method. One hundred patients were studied prospectively to determine the recurrence rate of stones and clinical outcome after successful percutaneous cholecystolithotomy. Follow up included both clinical assessment and ultrasound examination at 3,6 , and 12 months and then annual intervals thereafter. The overall stone recurrence rate was $31 \%$ at a mean follow up of 26 months (range, 3-50 months). By actuarial life table analysis, the cumulative proportion of gall stone recurrence was $7,19,28$, 35 , and $44 \%$ at $6,12,24,36$, and 48 months respectively. Of the 31 patients with recurrent stones; 17 remain asymptomatic, seven have experienced biliary colic, two abdominal pain, three non-specific upper gastrointestinal symptoms, and two jaundice secondary to common duct stones. Thirteen of the stone free patients have remained symptomatic; six with abdominal pain and seven with nonspecific upper gastrointestinal symptoms. Eight patients have subsequently had a cholecystectomy. No significant difference was found between the sex of the patient or the number of stones before treatment and the stone recurrence rates. The cumulative stone recurrence rate was significantly less in the $\mathbf{5 6}$ patients who received adjuvant chemolitholysis $(p<0.05)$. These data show that stone recurrence after successful percutaneous cholecystolithotomy occurs in the minority, and is usually asymptomatic. It is concluded that the technique remains justified in the management of selected patients with gall stones.
\end{abstract}

(Gut 1994; 35: 692-695)

are suitable for extracorporeal shockwave lithotripsy. ${ }^{3}$ Initial enthusiasm for these techniques has not been maintained as the treatment is prolonged and the success rates are disappointingly low $(38-50 \%) .^{2+5}$ By comparison, the advantages of percutaneous cholecystolithotomy over the other non-operative techniques are that it can be used in $78 \%$ of gall stone patients (irrespective of stone size, number or composition), ${ }^{6}$ a patent cystic duct is not required, the gall bladder can be cleared as a single stage procedure, and the method has a high success rate of $90 \%$ and over. . $^{6-12}$

There have been several studies investigating stone recurrence rates after complete clearance with oral dissolution therapy and extracorporeal shockwave lithotripsy, but to date, no data are available for after the percutaneous radiologically guided technique of stone removal. The aim of this study was to determine the stone recurrence rate and clinical outcome after successful percutaneous cholecystolithotomy.

\section{Patients and methods}

\section{PATIENTS}

Between January 1988 and December 1990, 113 patients had a percutaneous cholecystolithotomy for the treatment of symptomatic gall stones. Details of the selection criteria and technique have been previously described. ${ }^{6}$ Successful stone clearance was confirmed at the time of the procedure by endoscopic inspection of the gall bladder and by a negative cholecystogram 10 days later, before catheter removal. In 100 of 113 patients in whom the technique was considered successful a prospective follow up study has been performed.

\section{ADJUVANT THERAPY}

Adjuvant therapy was not given to the first 44 successfully treated patients. It was introduced after the finding that some tiny fragments, adherent to or embedded in the gall bladder mucosa, were difficult to remove completely and that some gall bladders showed cholesterolosis. Therefore, in the subsequent 56 patients adjuvant therapy with chenodeoxycholic acid $7 \mathrm{mg} / \mathrm{kg} /$ day and ursodeoxycholic acid $5 \mathrm{mg} / \mathrm{kg} /$ day was given for an arbitrary period of three months after the procedure. patients continue to require alternative, non or minimally invasive methods, including oral dissolution therapy, extracorporeal shockwave lithotripsy or percutaneous cholecystolithotomy for the management of their gall stones. As few as $10 \%$ of patients are suitable for oral dissolution therapy $^{2}$ and using the selection criteria laid down in the Munich study only $15 \%$ of patients
FOLLOW UP METHODS after percutaneous cholecystolithotomy, and then at yearly intervals. Follow up consisted of
Patients were reviewed at 3,6 , and 12 months 
an ultrasound examination and a clinical assessment.

\section{ULTRASOUND EXAMINATION}

Ultrasound examinations were performed with 3.5 and $5 \mathrm{mHz}$ transducers on either an Acuson 128 or an ATL Ultramark 4 DBF. Patients were fasted for a minimum of six hours and examined before and 30 minutes after a fatty meal (commercial chocolate bar, Mars bar). Details of the gall bladder contents (none, sludge or stones) and appearances of the gall bladder wall (normal, focal abnormalities or thickening) were recorded. A functional assessment of the gall bladder was made by measuring gall bladder volumes before and after a fatty meal. Volume (V) was calculated using the previously described ellipsoid method where $\mathrm{V}=0.52 \times$ height $\times$ width $\times$ length ${ }^{13}$ Percentage gall bladder contraction was calculated by dividing the change in volume before and after a fatty meal by the fasting volume $\times 100 \%$. Gall bladder emptying was considered satisfactory if a reduction in volume of $30 \%$ or more occurred on functional assessment, and poor or non-functional below this level.

\section{CLINICAL ASSESSMENT}

Symptoms were classified as follows: none, nonspecific upper gastrointestinal tract complaints (dyspepsia, flatulence), abdominal pain, biliary colic, and jaundice. Details of any additional gall stone related procedures including endoscopic retrograde cholangiography and cholecystectomy were recorded.

\section{POSSIBLE PREDISPOSING FACTORS}

Patients' sex and number of stones before treatment were recorded. Use of oral chemolitholysis in the last 56 patients of the series was noted.

\section{ANALYSIS AND STATISTICAL METHODS}

Actuarial life table analysis was used to calculate the cumulative proportion of stone recurrence. This analytical method compensates for variable follow up periods and takes into account patients who have been lost to follow up. Patients' sex and number of stones before percutaneous

Percentage cumulative probability of gall stone recurrence after percutaneous cholecystolithotomy.

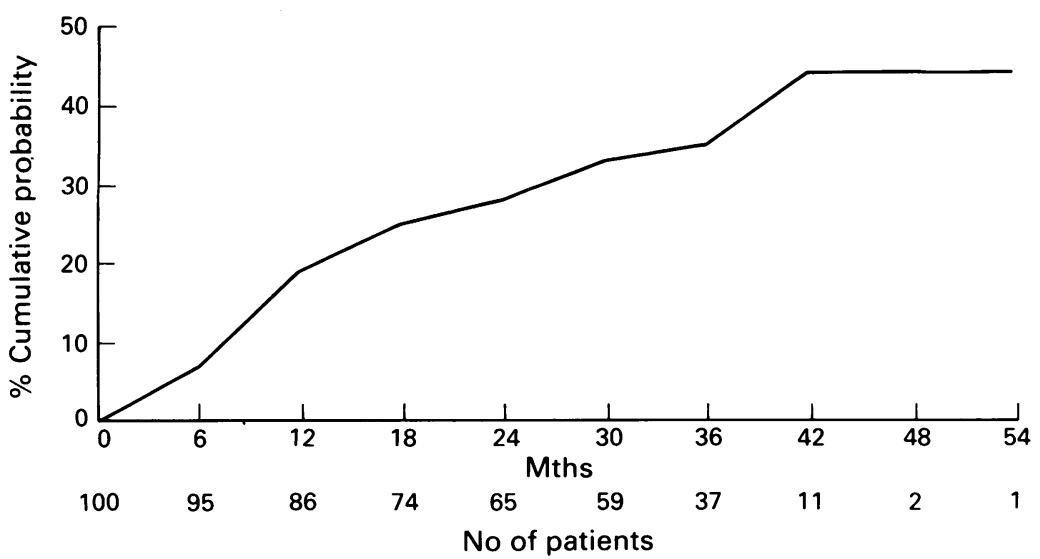

test to identify any significant difference between the stone free and recurrent stone groups. The log rank test was used to determine if there was any significant difference in the cumulative stone recurrence rates between the patients who did and those who did not receive adjuvant treatment.

\section{Results}

\section{LENGTH OF FOLLOW UP}

Follow up ranged from 3-50 months (mean, 26 months). During this period, seven patients have died, four from ischaemic heart disease, one from carcinomatosis (primary unknown), and two from pancreatic carcinoma. None of the deaths were procedure related. In the two cases of carcinoma of the pancreas all the imaging has been reviewed and the diagnosis was not evident either before the percutaneous cholecystolithotomy or for a 12 month period after treatment. Five patients were lost to follow up and two patients refused further follow up, both of whom remain asymptomatic.

\section{ULTRASOUND FINDINGS}

\section{Gall stone recurrence}

Overall the stone recurrence rate was $31 \%$. By actuarial life table analysis, the cumulative proportion of gall stone recurrence was $4,7,19,28$, 35 , and $44 \%$ at $3,6,12,24,36$, and 48 months respectively (Figure) with a plateau after 42 months. In three cases of recurrent stones (identified on two separate ultrasound examinations over a six month period), further follow up showed them to clear spontaneously. Sludge was seen within the gall bladder in nine patients, three of whom have developed stones on further follow up.

\section{Gall bladder wall}

Focal hyperechoic areas within the fundal wall of the gall bladder were identified in five patients. This was presumed to represent local scarring/ fibrosis after the fundal puncture. In five patients during follow up the gall bladder progressively reduced in volume, became thick walled (greater than $3 \mathrm{~mm}$ ), and non-functional.

\section{Gall bladder function}

Gall bladder function was satisfactory $(30 \%$ reduction in volume or greater gall bladder contraction) after percutaneous cholecystolithotomy in 84/96 patients (mean reduction in volume, $52 \%$ ). In 12 patients (of whom, three presented with an acute empyema and three with a non-functional gall bladder) the gall bladder either became or remained non-functioning (less than $30 \%$ volume reduction). In 14 cases the gall bladder was non-functional before percutaneous cholecystolithotomy because of impacted stones within Hartmann's pouch. Gall bladder function was successfully restored in 11 of these patients and also in six of 10 patients who presented with an acute empyema. Presence of a fundal 
'scar' did not significantly change gall bladder function.

\section{CLINICAL OUTCOME}

Of the 31 patients with recurrent stones: 17 remain asymptomatic, seven have experienced biliary colic, two abdominal pain, and three nonspecific upper gastrointestinal symptoms (flatulence and dyspepsia). Two patients developed jaundice secondary to common duct calculi, which required endoscopic sphincterotomy and stone removal. Thirteen of the stone free patients have remained symptomatic: six with abdominal pain and seven with non-specific upper gastrointestinal symptoms.

Eight patients have subsequently had a laparoscopic cholecystectomy, seven for recurrent, symptomatic stones and in one patient for persistent abdominal pain after an acute empyema. Adhesions between the fundus of the gall bladder and the peritoneum were present in all cases. In two patients the laparoscopic procedure was technically difficult requiring careful time consuming dissection of the adhesions. One of these patients developed a postoperative fluid collection within the gall bladder fossa, which quickly resolved after drainage under ultrasound guidance. No cases required conversion to an open cholecystectomy.

RELIABILITY OF BILIARY PAIN AS A PREDICTOR OF GALL STONE RECURRENCE

Biliary colic occurred in a total of seven patients, all of whom had recurrent stones.

\section{POSSIBLE PREDISPOSING FACTORS}

No significant difference was found between the sex of the patient or the number of stones before treatment and the stone recurrence rates. Eleven of 56 patients who received three months adjuvant therapy developed recurrent stones in comparison with 20 of 44 patients who did not receive any adjuvant therapy. Statistical analysis of the cumulative stone recurrence rates in these patients found this difference to be significant $(\mathrm{p}<0.05)$.

\section{Discussion}

Percutaneous cholecystolithotomy, like all treatment options that leave the gall bladder in situ are disadvantaged by the inherent risk of stone recurrence. Contrary with the intuitive assumption by some investigators, gall stone recurrence does not seem inevitable. In this series, after a successful percutaneous cholecystolithotomy stones recurred in $31 \%$ of patients with a cumulative probability of $44 \%$ at four years. These results are comparable with those reported for oral dissolution therapy and extracorporeal shockwave lithotripsy. ${ }^{14-18}$ Interestingly, we found that the risk of stone recurrence seems to decrease and plateau after the first few years. Similar findings have been seen after oral dissolution therapy. ${ }^{14-16}$ Using current selection criteria, the non-invasive methods have limited applications, being suitable for only $10-30 \%$ of patients with cholesterol stones, whereas percutaneous cholecystolithotomy can be used in 78\% of patients with gall stones, irrespective of size, number, and composition. ${ }^{6}$ Percutaneous cholecystolithotomy also has the advantage of a high stone clearance success rate ( $90 \%$ and over), which can be achieved as a single stage procedure. ${ }^{6-12}$

If gall stones recur, our experience would suggest that most patients will remain asymptomatic. Whether recurrent stones will act like de novo stones is unknown. Studies of the natural history of silent gall stones show that most of these patients will remain asymptomatic with a reported incidence of biliary colic of only $18 \%$ at 15 years. ${ }^{19} 20$ Therefore, it seems reasonable with current evidence to manage recurrent stones expectantly, with only symptomatic patients needing active treatment. During the follow up period only $8 \%$ of patients have had a subsequent laparoscopic cholecystectomy. It was successful in all cases and not precluded by adhesions formed secondary to the previous percutaneous approach, although it was made technicaly more difficult in two of the cases (one of whom initially presented with an empyema). Biliary colic was a reliable positive predictor of recurrent stones and did not occur in any of the stone free patients. Stone recurrences may have been the result of incomplete clearance of the gall bladder despite the more thorough endoscopic approach, because of tiny fragments adherent to or embedded in the mucosa, which in turn could act as a nidus for stone formation. This hypothesis is supported by the finding in this series of a significantly reduced stone recurrence rate in the 56 patients who were given adjuvant oral dissolution therapy in comparison with the other 44 patients.

Persistence or recurrence of symptoms after cholecystectomy is a well recognised phenomena, occurring in up to $50 \%$ of patients. ${ }^{21} 22$ After a successful percutaneous cholecystolithotomy within the stone free group, most patients became asymptomatic and to date, only 13 patients (19\%) have developed or remained symptomatic with either abdominal pain or nonspecific upper gastrointestinal symptoms. Although the gall bladder is considered to be dispensable, its preservation may result in a reduction of postcholecystectomy symptoms. A further consideration is the evidence of an increased risk of colonic carcinoma in women who have had cholecystectomy. ${ }^{23}$

It remains unclear why some subjects reform stones and others do not. If risk factors could be identified it would allow us to determine the patients who require close follow up and those who might benefit from prophylactic dissolution therapy. Potential predisposing factors for recurrence that have been identified include; exogenous oestrogens, ${ }^{24}$ the number of stones before treatment, with significantly higher recurrence rates in patients who initially had multiple stones than in those with solitary stones $^{24} 25$ and sudden weight loss in obese patients. ${ }^{26}$ Hood et al noted a significantly lower incidence of postdissolution recurrence in patients on therapeutic doses of non-steroidal anti-inflammatory drugs for rheumatic com- 
plaints. ${ }^{27}$ In this series, neither the sex of the patient or the number of stones before treatment showed any significant difference in stone recurrence rates. Data on non-steroidal anti-inflammatory therapy are not available for the patients in this study.

Both oral dissolution therapy and extracorporeal shockwave lithotripsy require a patent cystic duct and are of no value in the treatment of an acute empyema (when extracorporeal shockwave lithotripsy is contraindicated). As was the case in $10 \%$ of the patients, the technique can be used to clear the gall bladder of stones after the radiological drainage and clinical relief of an acute empyema. It is safe and can be performed in multiple stages under local anaesthetic. In this series, before percutaneous cholecystolithotomy therapy, the gall bladder was non-functional in 14 patients because of a stone impacted in Hartmann's pouch. In our experience, this does not preclude a successful procedure with the recovery of cystic duct patency and restoration of function, as occurred in 11 of these patients.

Cholelithiasis is a common problem in the elderly, occurring in up to $40 \%$ of patients greater than 70 years of age. ${ }^{28}$ After the sixth decade there is a steady increase in death and morbidity rates for elective cholecystectomy ${ }^{29}$ and in the emergency situation death rates may be as high as $19 \% .{ }^{30}$ In this series, $24 \%$ of the patients were over the age of 70 , there were no procedure related deaths and none of these patients have required a cholecystectomy. If recurrent stones do develop in elderly patients they will probably not live long enough to have problems, as a mean delay of eight years between stone formation and the development of symptoms has been calculated using carbon dating techniques. ${ }^{31}$ We currently recommend the minimally invasive percutaneous cholecystolithotomy procedure in the elderly and in those patients with coexisting medical conditions for whom operative management carries high risks.

In conclusion, gall stone recurrence is not inevitable after a successful percutaneous cholecystolithotomy. It occurs in a few patients, is usually asymptomatic, and does not preclude a subsequent laparoscopic cholecystectomy (if and when required). It offers a valuable therapeutic alternative to conventional surgery in the small but ever increasing group of high risk and elderly patients and has inherent advantages over the other non-invasive methods.

$1 \mathrm{McSh}$ rry CK. Cholecystectomy: the gold standard. Am $\mathcal{F}$ Surg 1989; 158: 174-8.

2 Maton PN, Iser JH, Reuben A, Saxton HM, Murphy GM, Dowling RH. Outcome of chenodeoxycholic acid (CDCA) treatment in 125 patients with radiolucent gallstones. Medicine 1982; 61: 85-96.

3 Brink JA, Simeone JF, Mueller PR, Richter JM, Prien EL, Ferrucci JT. Physical characteristics of gallstones removed at cholecystectomy: implications for extracorporeal shockwave lithotripsy. $A \mathscr{F} R$ 1988; 151: 927-31.
4 Fache JS, Rawat B, Burhenne HJ. Extracorporeal cholecystolithotripsy without oral chemolitholysis. Radiology 1990; 177: 719-21.

5 Zeman RK, Davros WJ, Goldberg JA, Fanney D, Forer LE, Garra BS, et al. Gallstone lithotripsy: results when number of stones is excluded as a-criterion for treatment. AYR 1991; 157: 747-52.

6 Cheslyn-Curtis S, Gillams AR, Russell RCG, Donald JJ, Lake SP, Ainley CA, et al. Selection, management, and early outcome of 113 patients with symptomatic gall stones treated by percutaneous cholecystolithotomy. Gut 1992; 33: 1253-9.

7 Chiverton SG, Inglis JA, Hudd C, Kellett MJ, Russell RCG, Wickham JEA. Percutaneous cholecystolithotomy: the first 60 patients. $B M \mathcal{F} 1990 ; 300$ : 1310-2.

8 Cope C, Burke DA, Meranze SG. Percutaneous extraction of gallstones in 20 patients. Radiology 1990; 176: 19-24.

9 Hruby W, Stackl W, Urban M, Armbruster C, Marberger M. Percutaneous endoscopic cholecystolithotripsy. Radiology

10 Kellett MJ, Wickham JEA, Russell RCG. Percutaneous cholecystolithotomy. BMF 1988; 296: 453-7.

11 Kerlan RK, La Berge JM, Ring EJ. Percutaneous cholecystolithotomy: preliminary experience. Radiology 1985; 157: 653-6.

12 Picus D, Marx MV, Hicks ME, Lang EV, Edmundowicz SA. Percutaneous cholecystolithotomy: preliminary experience and technical considerations. Radiology 1989; 173: 487-91.

13 Dodds WJ, Groh WJ, Darweesh RMA, Lawson TL, Kishk SMA, Kern MK. Sonographic measurement of gallbladder volume. AFR 1985; 145: 1009-10.

14 Dowling RH, Gleeson DC, Hood KA, Ruppin DC, BritishBelgian Gallstone Study Group. Gallstone recurrence and post dissolution management. In: Paumgartner G, Stiehl A, post dissolution management. In: Paumgartner G, Stiehl A, Gerok W, eds. Bile
Press, 1987: 355-67.

15 Lanzini A, Jazrawi RP, Kupfer RM, Maudgal DP, Joseph AEA, Northfield TC. Gallstone recurrence after medical dissolution. An overestimated threat? $\mathcal{F}$ Hepatol 1986; 3 : $241-6$.

16 O'Donnell LDJ, Heaton KW. Recurrence and re-recurrence of gall stones after medical dissolution: longterm follow up. Gut 1988; 29: 655-8.

17 Sackmann M, Ippisch E, Sauerbruch T, Holl J, Brendel W, Paumgartner G. Early gallstone recurrence rate after successful shock-wave therapy. Gastroenterology 1990; 98: 392-6.

18 Darzi A, McCollum P, Leahy A, Tanner WA, Keane FBV. Gallstone recurrence after successful shock wave lithotripsy. Brf Surg 1990; 77: A703.

19 Gracie WA, Ransohoff DF. The natural history of silent gallstone. The innocent gallstone is not a myth. $N$ Engl f Med 1982; 307: 798-800

20 Gibney EJ. Asymptomatic gallstones. Br $\mathcal{F}$ Surg 1990; 77: 36872.

21 Bates T, Mercer JC, Harrison M. Symptomatic gall stone disease before and after cholecystectomy. Gut 1984; 25 A579-80.

22 Ros E, Zambon D. Postcholecystectomy symptoms. A prospective study of gallstone patients before and two years after surgery. Gut 1987; 28: 1500-4.

23 Linos DA, Berad CM. O'Fallon WM, Dockerty MB, Beart RW, Kurland LT. Cholecystectomy and carcinoma of the colon. Lancet 1981; ii: 379-81.

24 Scholz DG, McCullough JE, Peterson BT, Thistle JL. Gallstone recurrence following complete dissolution with bile stone recurrence following complete dissolution with bile acid the

25 Villanova N, Bazzoli F, Taroni F, Frabboni R, Mazzella G Gesti $D$, et al. Gallstone recurrence after successful oral bile acid treatment. Gastroenterology 1989; 97: 726-31.

26 Broomfield PH, Chopra R, Sheinbaum RC, Bonorris GG Silverman A, Schoenfield LJ, et al. Effects of ursodeoxycholic acid and aspirin on the formation of lithogenic bile and gallstones during loss of weight. $N$ Engl $\mathcal{F}$ Med 1988; 319: 1567-72.

27 Hood K, Gleeson D, Ruppin DC, Dowling RH. Prevention of gallstone recurrence by non-steroidal anti-inflammatory drugs. Lancet 1988; ii: $1223-4$.

28 Glenn F, Dillon LD. Developing trends in acute cholecystitis and choledocholithiasis. Surg Gynecol Obstet 1980; 151: 52832 .

29 Greenburg AG, Salk RP, Farris JM, Peskin GW. Operative mortality in general surgery. Am $\mathcal{F}$ Surg 1982; 144: 22-8.

30 Houghton PWJ, Jenkinson LR, Donaldson LA. Cholecystectomy in the elderly: a prospective study. BrF Surg 1985; 72: $220-2$.

31 Mok HY, Druffel ER, Rampone WM. Chronology of cholelithiasis. Dating gallstones from atmospheric radiocarbon produced by nuclear bomb explosions. NEngl f Med 1986; 314: 1075-7. 